\title{
Classification of the Most Influential Maritime Accident Types using Grey Theory
}

\author{
Dong-Jin Kim¹)
}

\begin{abstract}
In recent years, the number of maritime accidents in Korean waters has been increasing dramatically. Fishing vessel accidents account for around $70 \%$ of all accidents. However, there have been limited studies on fishing vessel accidents relative to non-fishing vessel accidents. The government has announced maritime plans to reduce both the frequency of these accidents, as well as the fatalities resulting from them. The purpose of the research is to identify the influential accident types on accident frequency and fatality. We accordingly classify the major accident types leading to fishing vessel accidents into two categories, frequency and fatality, using grey relational analysis which is an efficient ranking technique to determine the most influential accident types. For this study, data from nine types of fishing vessel accidents over the last 5 years (2014 to 2018) are used. The results show that for frequency category, engine failure, others, collision, and safety precautions were the most influencing types, whereas touching and sinking were shown to be the least influencing accident types. For fatality category, safety precautions, collision, and grounding were the most influencing accident types whereas touching, engine failure, and others were the least influencing accident types. The findings demonstrate that more attention should be paid to engine failure and safety precautions to reduce maritime accidents.
\end{abstract}

Keywords: Grey Relational Analysis, Fishing Vessel Accident, Accident Type, Accident Frequency, Accident Fatality

\section{Introduction}

Maritime accidents are less frequent than other industrial accidents. However, when an accident occurs, it not only results in human and physical damage, but also often weakens national competitiveness[1]. The tragic capsizing of the Sewol ferry on April 16th, 2014 claimed over 300 innocent lives and resulted in economic damage to Korea worth 3.8 million dollars. Most of the victims were high school students. A cargo overload and unsafe operation of the vessel were the major causes of the accident. The number of accidents from 2013 to 2017 has shown an increasing trend and the number of accidents in 2017 was more than double the number of accidents in 2013. Since, fishing vessel accidents account for about $68 \%$ of maritime accidents,

Received(January 29, 2020), Review Result(1st: February 28, 2020, 2nd: April 20, 2020), Accepted(May 27, 2020)

1) (Professor) 46241 Dept. International Trade, Pusan National University, Busan, Korea

email: ssskdj@hanmail.net 
we decided to limit our investigation to fishing vessel accidents.

Although, the Korean government has drawn up a national-level plan to prevent maritime accidents, the number of accidents has been increasing over the past few years. Researches on fishing vessel accidents have not actively done unlike other ship accident cases, and most of the existing studies mainly focus on either types or causes of accidents. We in this study, identify the main types of fishing vessel accidents in two categories, accident frequency and accident fatality. For this study, nine types of accidents (collision, touching, sinking, capsizing, fire/explosion, safety precautions, engine failure, grounding, and others) from Korean Maritime Safety Tribunal (KMST) are used over the 2014-2018 period. For more accurate analysis of the fatality, we included the number of injured and missing persons and considered them to be fatality equivalents.

Usually, statistical analysis needs a large amount of sampling data; however, grey relational analysis requires less data[2]. In this study, we therefore rank the nine accident types using grey relational analysis (GRA), which is a widely used technique when the data available are not sufficient and/or uncertain. The findings of the GRA will help answer the following questions; What are the important influential types of accidents on frequency and fatality and which accident reduction measures should be implemented for different accident types?

In section 2, we summarize some recent studies on fishing vessel accidents and the application of grey relational analysis; in section 3, we introduce GRA method for ranking the accident types. In section 4, the most influential types based on their level of influence on the frequency and fatality of fishing vessel accidents using GRA. Finally, in section 5, the conclusions and limitations of this study, as well as the scope for future research are discussed.

\section{Literature Review}

Most research on fishing vessel accidents in Korea uses primary accident data from the KMST based on which ways to enhance safety are suggested. Since the accidents are classified into different categories, studies mainly focus on the analysis of specific type(s) of accidents, causes of accidents, and corresponding accident mitigation measures[3]. Among studies on accident types Jung et al.[4] considered capsizing, whereas Cho et al.[5] and Jung[6] considered engine failure and collision. Additionally, risk assessment techniques were used to analyze fishing vessel accidents and propose mitigation measures[7][8]. Recently, Sur and Kim[3] used the fuzzy concept to analyze fishing vessel accidents quantitatively and compared the resulting risk level for each accident type against the "as low as reasonably practicable" (ALARP) criteria. 
Grey relation analysis (GRA) is based on similar or dissimilar relationships between the various variables of a process. It helps rank alternatives for decision making[9]. This method quantifies the influence of various factors and their relations called the whitening of factor relation. GRA is unlike traditional statistical analysis that considers the relationship between variables[2]. Relevant studies that have applied the GRA are as follows. Liu and $\mathrm{Wu}[2]$ investigated the major human factors leading to ship collisions using accident data over a 10year span. Among the 13 factors, improper lookout and improper ship handling were found to be the most unsafe factors, whereas improper routing plan and failure to fix were the least unsafe. Su et al.[10] performed GRA to rank the types of oil spill accidents from oil tankers. $\mathrm{Yu}$ and $\mathrm{Wu}[11]$ found nine factors that influenced the development of the tourism industry the most in the Guangdong province of China. Cai[12] chose the best mode for freight transportation in Jiangxi province, China in an effort to enhance the economy of the region. GRA has also been effectively applied in various multi-criteria decision-making (MCDM) problems to determine the rankings of alternatives. Stanujkic et al.[13] considered several widely used MCDM techniques including GRA and discussed the advantages and disadvantages of each method by ranking Serbian banks.

\section{GRA for Ranking the Most Influential Accident Types in Fishing Vessel}

\section{Accidents}

Existing methods applied in MCDM problems should calculate proper weights for criteria. However, GRA provides objective ranking results without assigning specific weights[3]. Grey relational grade (GRG) obtained from GRA is to describe the relationships between factors and to determine the factors that significantly influence certain defined objectives[14]. Using GRA one can easily rank the influencing factors using dependent and independent variables. For this study, we rank the most influential types of fishing vessel accidents using GRA. The general procedure for GRA is the following.

1) Determination of reference sequence

A reference sequence (benchmarking sequence) is selected.

2) Normalization of original data

If original data are measured using different units, they need to be normalized based on the benefit or cost type to make them dimensionless.

3) Calculation of grey relational coefficient $\left(\gamma_{i j}\right)$ 


$$
\gamma_{i j}=\frac{\Delta_{\min }+\zeta \Delta_{\max }}{\Delta_{i j}+\zeta \Delta_{\max }}
$$

where $\Delta_{i j}$ is absolute difference between reference value of year $\mathrm{j}$ and value of accident type i to j, $\Delta_{\min }=\min \Delta_{i j}, \quad \Delta_{\max }=\max \Delta_{i j}$ and $\zeta$ is distinguishing coefficient with $\zeta$ $\in[0,1]$ (usually $\zeta=0.5$ ).

4) Calculation of GRG

The final step of grey relational analysis is to calculate the grey relational grade $\left(\Gamma_{i}\right)$ for each accident type i using grey relational coefficient $\left(\gamma_{i j}\right)$.

$$
\Gamma_{i}=\frac{1}{N} \sum_{j} \gamma_{i j}
$$

5) Determination of ranking of each alternative

The higher the value of GRG, the higher the ranking of the accident type and consequently, the accident type with the highest GRG value is the most influential. For normalization of original accident data we employ the following commonly used method[2][11][12].

$$
x_{i}^{*}(j)=\frac{x_{i(j)}}{\frac{1}{N} \sum_{j=1}^{N} x_{i(j)}},
$$

where $x_{i}{ }^{*}(j)$ and $x_{i(j)}$ are normalized and original values of accident type $\mathrm{i}$ to year $\mathrm{j}$, respectively and $\mathrm{N}$ is the number of years to be analyzed. For the use of GRA, a flow chart is organized as follows.

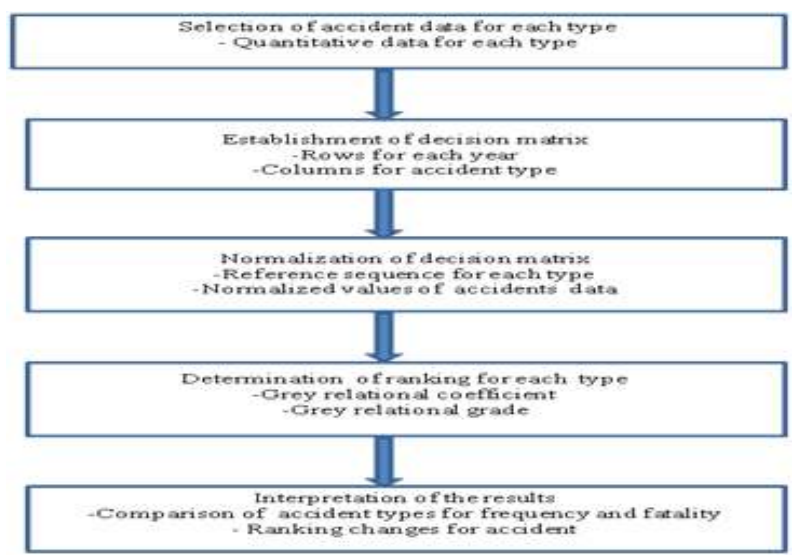

[Fig. 1] Flowchart for GRA 


\section{Determination of the Most Influential Accident Types}

\subsection{Determination of the Most Influential Accident Types on Accident Frequency}

Using the fishing vessel accident data from KMST over the 2014-2018 period, the frequencies of nine types of accidents are summarized (see [Table 1]), where the nine accident types are independent variables and accident frequency is the dependent variable. The accident frequency forms the reference sequence.

[Table 1] Fishing Vessel Accident Frequency (2014-2018)

\begin{tabular}{|c|c|c|c|c|c|c|c|c|c|c|}
\hline & Frequency & COL & TOU & GRO & CAP & FIR & SIN & ENG & SAF & OTH \\
\hline 2014 & 896 & 102 & 3 & 74 & 22 & 74 & 11 & 252 & 81 & 277 \\
\hline 2015 & 1461 & 159 & 12 & 65 & 25 & 65 & 23 & 477 & 119 & 516 \\
\hline 2016 & 1646 & 145 & 7 & 112 & 36 & 91 & 13 & 523 & 113 & 606 \\
\hline 2017 & 1778 & 176 & 13 & 116 & 47 & 72 & 13 & 557 & 121 & 663 \\
\hline 2018 & 1846 & 174 & 7 & 106 & 28 & 90 & 23 & 588 & 136 & 694 \\
\hline
\end{tabular}

(COL: Collision, TOU: Touching, GRO: Grounding, CAP: Capsizing, FIR: Fire/Explosion, SIN: Sinking, ENG: Engine failure, SAF: Safety precautions, OTH: Others)

Using equation (3) normalized accident data for each year is shown in [Table 2].

[Table 2] Normalization of Data

\begin{tabular}{|c|c|c|c|c|c|c|c|c|c|c|}
\hline & Frequency & COL & TOU & GRO & CAP & FIR & SIN & ENG & SAF & OTH \\
\hline 2014 & 0.58 & 0.67 & 0.35 & 0.78 & 0.69 & 0.94 & 0.66 & 0.52 & 0.71 & 0.50 \\
\hline 2015 & 0.95 & 1.05 & 1.42 & 0.68 & 0.79 & 0.82 & 1.38 & 0.99 & 1.04 & 0.93 \\
\hline 2016 & 1.07 & 0.95 & 0.83 & 1.18 & 1.13 & 1.16 & 0.78 & 1.09 & 0.99 & 1.09 \\
\hline 2017 & 1.16 & 1.16 & 1.54 & 1.22 & 1.48 & 0.91 & 0.78 & 1.16 & 1.06 & 1.20 \\
\hline 2018 & 1.21 & 1.15 & 0.83 & 1.12 & 0.88 & 1.14 & 1.38 & 1.22 & 1.19 & 1.25 \\
\hline
\end{tabular}

With equation (1) we calculate grey relational coefficients for each year.

[Table 3] Grey Relational Coefficient

\begin{tabular}{|c|c|c|c|c|c|c|c|c|c|}
\hline & COL & TOU & GRO & CAP & FIR & SIN & ENG & SAF & OTH \\
\hline 2014 & 0.73 & 0.50 & 0.55 & 0.68 & 0.40 & 0.76 & 0.79 & 0.66 & 0.73 \\
\hline 2015 & 0.71 & 0.33 & 0.46 & 0.58 & 0.65 & 0.35 & 0.86 & 0.73 & 0.92 \\
\hline 2016 & 0.66 & 0.49 & 0.69 & 0.80 & 0.74 & 0.44 & 0.95 & 0.73 & 0.92 \\
\hline 2017 & 1 & 0.38 & 0.80 & 0.42 & 0.49 & 0.38 & 0.99 & 0.69 & 0.86 \\
\hline 2018 & 0.80 & 0.38 & 0.72 & 0.42 & 0.79 & 0.57 & 0.94 & 0.93 & 0.83 \\
\hline
\end{tabular}


Grey relational coefficients for nine accident types over 5 years are shown in [Fig. 2]. If the coefficients are closer to 1 , the corresponding accident type has more influence on the accident frequency. As shown in [Fig. 2] collision (COL), engine failure (ENG), safety precautions (SAF), and others (OTH) have relatively higher coefficients compared with other types of accidents.

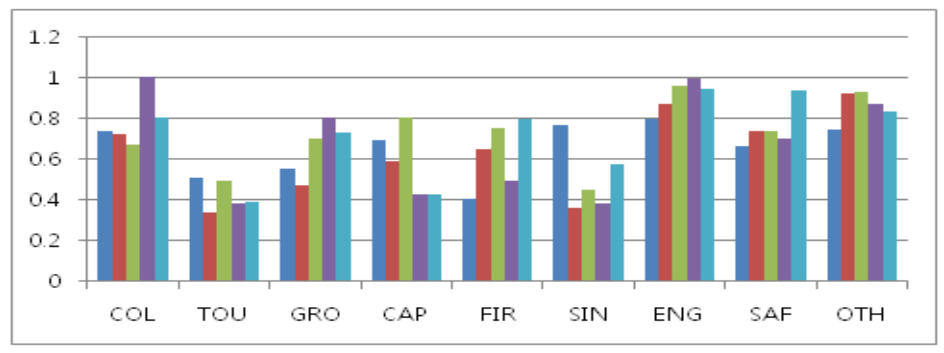

[Fig. 2] Grey Relational Coefficients for Accident Type from 2014-2018

Using equation (2), GRG for each accident type is seen in [Table 4]. Engine failure (ENG) is ranked first with a GRG of 0.9114 , followed by others (OTH), collision (COL), and safety precautions (SAF), whereas touching (TOU) and sinking (SIN) are the least influential accident types.

[Table 4] Grey Relational Grade for Each Accident Type

\begin{tabular}{|c|c|c|c|c|c|c|c|c|c|}
\hline & COL & TOU & GRO & CAP & FIR & SIN & ENG & SAF & OTH \\
\hline GRG & 0.78 & 0.42 & 0.64 & 0.58 & 0.61 & 0.50 & 0.91 & 0.75 & 0.85 \\
\hline Ranking & 3 & 9 & 5 & 7 & 6 & 8 & 1 & 4 & 2 \\
\hline
\end{tabular}

\subsection{Determination of the Most Influential Accident Types on Accident Fatality}

The injured and missing people are considered to be fatality equivalents by assigning them weights based on Kim et al.[15], where weights for the dead, injured, and missing are 1, 0.996, and 0.043 , respectively. The resulting fatalities of each type are shown in [Table 5].

[Table 5] Accident Fatality (2014-2018)

\begin{tabular}{|c|c|c|c|c|c|c|c|c|c|c|}
\hline & Fatality & COL & TOU & GRO & CAP & FIR & SIN & ENG & SAF & OTH \\
\hline 2014 & 140.39 & 21.71 & 0.21 & 1.08 & 6.99 & 14.36 & 54.89 & 0.08 & 40.89 & 0.12 \\
\hline 2015 & 88.92 & 15.6 & 0 & 1 & 22.23 & 1.08 & 6.08 & 0.04 & 42.83 & 0.04 \\
\hline 2016 & 112.33 & 24.50 & 0.08 & 1.63 & 13.00 & 3.42 & 2.08 & 0 & 67.28 & 0.30 \\
\hline 2017 & 110.72 & 35.22 & 1.94 & 1.94 & 19.18 & 1.17 & 1.99 & 0 & 49.21 & 0.04 \\
\hline 2018 & 98.07 & 22.52 & 0.04 & 2.3 & 23.38 & 0.47 & 1.04 & 0 & 45.23 & 3.07 \\
\hline
\end{tabular}


GRA is calculated in the same way as accident frequency, and the results are shown in the following tables and figures. The Grey relational coefficient for each type is shown in [Table 6].

[Table 6] Grey Relational Coefficients

\begin{tabular}{|c|c|c|c|c|c|c|c|c|c|}
\hline & COL & TOU & GRO & CAP & FIR & SIN & ENG & SAF & OTH \\
\hline 2014 & 0.82 & 0.67 & 0.74 & 0.66 & 0.43 & 0.37 & 0.45 & 0.79 & 0.60 \\
\hline 2015 & 0.91 & 0.67 & 0.90 & 0.77 & 0.75 & 0.83 & 0.66 & 0.96 & 0.69 \\
\hline 2016 & 0.99 & 0.67 & 0.99 & 0.87 & 0.90 & 0.66 & 0.62 & 0.83 & 0.73 \\
\hline 2017 & 0.78 & 0.34 & 0.88 & 0.93 & 0.70 & 0.66 & 0.62 & 1 & 0.64 \\
\hline 2018 & 0.97 & 0.68 & 0.75 & 0.77 & 0.68 & 0.67 & 0.65 & 0.98 & 0.33 \\
\hline
\end{tabular}

Grey relational coefficients for nine accident types for 5 years are shown in [Fig. 3].

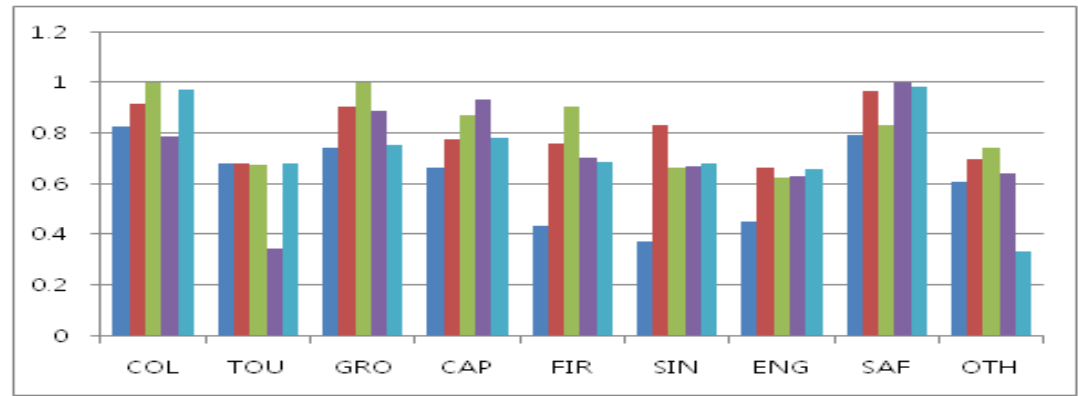

[Fig. 3] Grey Relational Coefficients for Accident Type from 2014-2018

From [Fig. 3] collision (COL), grounding (GRO), capsizing (CAP), and safety precautions (SAF) have higher coefficients compared to other types of accidents, whereas touching (TOU), engine failure (ENG), and others (OTH) have lower coefficients. The grey GRG for each accident type is shown in [Table 7]. Safety precaution (SAF) is the most influential type of accident with a GRG of 0.9148 , followed by collision (COL) and grounding (GRO), whereas touching (TOU), engine failure (ENG), and others (OTH) have the least influence.

[Table 7] Grey Relational Grades for Each Accident Type

\begin{tabular}{|c|c|c|c|c|c|c|c|c|c|}
\hline & COL & TOU & GRO & CAP & FIR & SIN & ENG & SAF & OTH \\
\hline GRG & 0.89 & 0.61 & 0.85 & 0.80 & 0.69 & 0.64 & 0.60 & 0.91 & 0.60 \\
\hline Ranking & 2 & 7 & 3 & 4 & 5 & 6 & 8 & 1 & 9 \\
\hline
\end{tabular}

From [Table 4] and [Table 7], GRGs for frequency and fatality are shown to be different as shown in [Fig. 4]. 


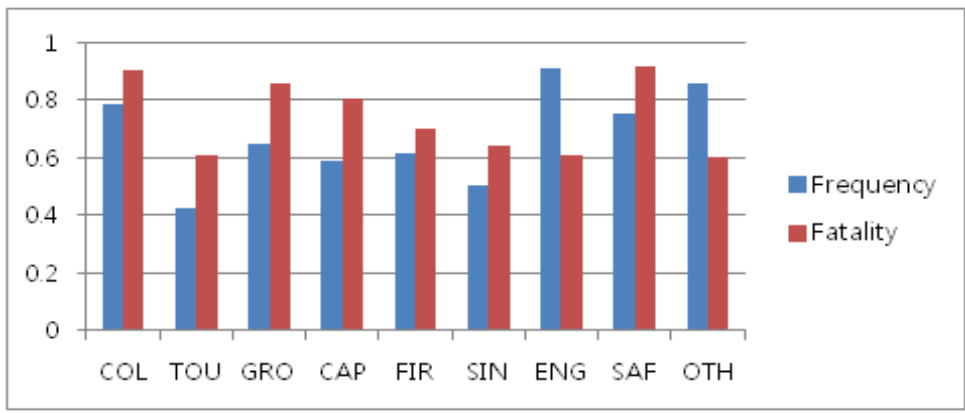

[Fig. 4] GRG Comparison between Frequency and Fatality for each Type

\section{Conclusion}

To establish policies related to maritime accidents one needs to classify the major types of accidents that affect the overall frequency and fatality of accidents. In this study, using grey relational analysis, we identify the type of accidents that had the most influence over the 2014-2018 period. Engine failure, others, collision, and safety precautions were the types of accidents that had the most influence on frequency, whereas touching and sinking had the least influence.

Safety precautions, collision, and grounding were the types of accidents that had the most influence on fatality, whereas touching, engine failure, and others had the least influence. The results of the analysis are summarized in the following [Table 8], where the average represents the average GRGs of frequency and fatality. Collision is the most influential type of accident on average. Therefore, more attention should be paid to engine failure, safety precautions and collision to reduce maritime accidents. The findings will help to implement different accident mitigation measures for different accident categories.

[Table 8] Ranking of Grey Relational Grades for Accident Types

\begin{tabular}{|c|c|c|c|c|c|c|c|c|c|}
\hline & COL & TOU & GRO & CAP & FIR & SIN & ENG & SAF & OTH \\
\hline Frequency & 0.78 & 0.42 & 0.64 & 0.58 & 0.61 & 0.50 & 0.91 & 0.75 & 0.85 \\
\hline Fatality & 0.89 & 0.61 & 0.85 & 0.80 & 0.69 & 0.64 & 0.60 & 0.91 & 0.60 \\
\hline Average & 0.83 & 0.51 & 0.74 & 0.69 & 0.65 & 0.57 & 0.75 & 0.83 & 0.72 \\
\hline $\begin{array}{c}\text { Overall } \\
\text { ranking }\end{array}$ & 1 & 9 & 4 & 6 & 7 & 8 & 3 & 2 & 5 \\
\hline
\end{tabular}

For the study, we only considered fishing vessel accidents from 2014-2018[16]. However, for greater understanding regarding the types of accidents that influence frequency and fatality, 
we need to broaden the scope of the study to include other maritime accidents such as accidents involving oil tankers, container ships, passenger ships, and bulk ships. Additionally, to observe the effect of both frequency and fatality, a frequency-fatality matrix using the result of grey relational analysis needs to be constructed to direct future research. Since each accident type has different causes, major accident causes should be classified in detail to help decision-makers implement different accident reduction measures for different accident types.

\section{Acknowledgements}

This study was supported by the Fund for Humanities \& Social studies at Pusan National University 2019.

\section{References}

[1] Y. K. Won, D. J. Kim, Quantitative Risk Assessment of Maritime Accident for Different Types in Korea, Asia-pacific Journal of Convergent Research Interchange, (2018), Vol.4, No.3, pp.19-29.

[2] Z. Liu, Z. Wu, The Identification of Human Unsafe Acts in Maritime Accidents with Grey Relational Analysis, Proceedings of the Korean Institute of Navigation and Port Research Conference, (2004), Aug 1; Seoul, Korea.

[3] J. M. Sur, D. J. Kim, Comprehensive Risk Estimation of Maritime Accident Using Fuzzy Evaluation Method -Focusing on Fishing Vessel Accident in Korean Waters-, The Asian Journal of Shipping and Logistics, (2020), Vol.36, No.3, pp.127-135, DOI: https://doi.org/10.1016/j.ajsl.2019.12.013.

[4] C. H. Jung, Y. S. Park, J. S. Kim, S. W. Kim, A Study on the Cause Analysis for the Capsizing Accident in Fishing Vessels, Journal of Fisheries and Marine Sciences Education, (2012), Vol.24, No.1, pp.1-8.

[5] H. K. Cho, B. S. Park, D. H. Kang, S. S. Kim, The Main Factor and Counter plan for Marine Accidents in Korea, Journal of Fisheries and Marine Sciences Education, (2017), Vol.29, No.3, pp.746-756.

[6] C. H. Jung, A study on the Improvement of Safety by Accidents Analysis of Fishing Vessels, Journal of Fisheries and Maritime Sciences Education, (2018), Vol.30, No.1, pp.176-186.

[7] S. H. Kim, H. S. Kim, I. K. Kang, W. S. Kim, An Analysis on Maritime Casualties of Fishing Vessel by FTA Method, Journal of the Korean Society of Fisheries Technology, (2017), Vol.53, No.4, pp.430-436.

[8] Y. K Won, D. J. Kim, Risk Analysis and Selection of the Main Factors in Fishing Vessel Accidents Through a Risk Matrix, Journal of the Korean Society of Marine Environment \& Safety, (2019), Vol.25, No.2, pp.139-150.

[9] P. A. Nayakappa, A. Gaurish, G. Mahesh, Grey Relation Analysis Methodology and its Application, Research Review International Journal of Multidisciplinary, (2019), Vol.4, No.2, pp.409-411. 
[10] D. T. Su, F. M. Tzu, C. H. Cheng, Investigation of Oil Spills from Oil Tankers through Grey Theory: Events from 1974 to 2016, Journal of Marine Science and Engineering, (2019), Vol.7, pp.373-386.

[11] T. Yu, C. Wu, A Grey Relational Analysis of the Influence Factors of Tourism Industry in Guangdong Province, 2nd International Conference on Humanities and Social Science Research, (2016), July 29-31; Singapore.

[12] J. Cai, Grey Relational Analysis of Regional Logistics and Economies in Jiangxi Province, Revista de la Facultad de Ingenieria, (2017), Vol.32, No.12, pp.64-68.

[13] D. Stanujkic, B. Dordevic, M. Dordevic, Comparative Analysis of Some Prominent MCDM Methods: A Case of Ranking Serbian banks, Serbian Journal of Management, (2013), Vol.8, No.2, pp.213-241.

[14] R. Sallehuddin, S. M. H. Shamsuddin, S. Z. Mohd Hashim, Grey Relational Analysis and its Application on Multi variate Time Series, IEEE 2008 Eighth International Conference on Intelligent Systems Design and Applications, (2008), November 26-28; Kaohsiung, Taiwan.

[15] W. S. Kim, J. H. Lee, S. J. Kim, H. S. Kim, Y. W. Lee, A Basic Study on Control Factor for the Marine Casualties of Fishing Vessel in Korea, Journal of Korea Society for Fishery Technology, (2013), Vol.49, No.1, pp.40-50.

[16] D. J. Kim, A study on influencing accident types of maritime accident using grey theory, 2nd Domestic and International Integration Conference, (2020), April 25; Chungnam National University, Korea. 